\title{
Perch-height specific predation on tropical lizard clay models: implications for habitat selection in mainland neotropical lizards
}

\author{
John E. Steffen ${ }^{1}$ \\ 1. Department of Biological Sciences, Auburn University, Auburn, AL 36849 USA; steffje@auburn.edu \\ Received 11-IV-2008. Corrected 10-I-2009. Accepted 09-II-2009.
}

\begin{abstract}
Predation has been hypothesized to be a strong selective force structuring communities of tropical lizards. Comparisons of perch height and size-based predation frequencies can provide a unique window into understanding how predation might shape habitat selection and morphological patterns in lizards, especially anoles. Here I use plasticine clay models, placed on the trunks of trees and suspended in the canopy to show that predation frequency on clay models differs primarily according to habitat (canopy vs. trunk-ground), but not according to size. These data are discussed in light of observed lizard abundances in the lowland forests of Costa Rica, and are presented as partial explanation for why fewer lizards are found in tree canopies, and more lizards are found on ground-trunk habitats. Rev. Biol. Trop. 57 (3): 859-864. Epub 2009 September 30.
\end{abstract}

Key words: canopy, clay model, lizard, predation, tree trunk.

It has been speculated that predation may be an important selective force effecting patterns of body size and habitat choice in mainland anoles (Lister 1981, Andrews and Rand 1982), in part because they do not appear to conform well to Caribbean island lizard ecomorph classification. That is, body size, limb length and habitat associations are different from island anoles (Irschick et al. 1997). Determination of the extent to which predation influences body size or habitat choice remains largely unknown because predation on anoles is difficult to observe (Schoener and Schoener 1978, Wunderle 1981, Adolph and Roughgarden 1983) and to quantify (Adolph and Roughgarden 1983). Past studies which suggest that predation may be important to structuring mainland anole communities have relied on indirect methods of assessment, such as annual survivorship (Andrews and Rand 1982) or behavioral observations (Wunderle
1981). Direct behavioral observations are of limited use in predation assessment because they do not allow quantification of predation at times and places where there are no observers present. That is, behavioral observations only tell us something about individuals we know have been attacked. The use of annual survivorship to infer predation rates is weak because it confuses total annual survivorship with mortality due to predation alone. Because survivorship values cannot quantify the number of individuals lost in a year to non-predator causes, in addition to those killed by predators, the values quantified and assessed may be an overestimate. Moreover, this method is limited to studying predation on anoles in localities or habitats in which lizards are easy to capture, mark, and recapture, but does not allow researchers to gain insight about predation in environs that are less observable. 
Here I quantify canopy- and tree-trunkbased predation frequency for small and moderate-sized clay lizards in a neotropical lowland primary forest. I compare predation frequency between size classes and habitats (trunk-ground and canopy) to test the ideas that predation frequencies are related to a) body size and b) vertical location / perch height in the forest canopy, thereby providing support for the hypothesis that observed patterns in body size, perch location, and species number is in part related to predation pressure.

\section{MATERIALS AND METHODS}

Clay models: To determine if attack frequency differs among size classes or perch height of Norops lizards, I fashioned plasticine clay by hand, into shapes that resemble moderate-sized anoles (e.g. N. biporcatusthe largest canopy dwelling anole present in wet, lowland tropical forests of Central America; SVL= $100 \mathrm{~mm} \mathrm{SVL}$ ) and smallsized anoles (e.g. N. limifrons-a common, small, trunk-ground anole widely distributed in wet, lowland tropical forests of Central America; $\mathrm{SVL}=45 \mathrm{~mm}$ ). Green clay was used for models of lizards placed in the forest canopy, while brown clay was used for models of lizards placed on the trunks of trees. I did not attempt to determine if clay model color (brown versus green) influenced predation frequency by using both brown and green models in both canopy and tree environments. The clay model colors were chosen to mimic the color of their associated environmental backgrounds because there is a generally tendency for lizard dorsal body color (as well as entire body color) to match its background in nature, and this is especially true for Anolis lizards at La Selva Biological Station (personal observation). However, the color for these clay models were chosen because they represent the non-UV components of colors exhibited by each species the replicas were modeled for. Dorsal body surfaces of anoles do not reflect UV, at least among species in published literature (Macedonia et al. 2003). Thus, I assume that the colors chosen for the clay models do not appear abnormal to predators, and do not confound attempts to quantify predation frequency.

Clay models have been used to study rates of predation experienced by aposematicallycolored snakes and bird nests and eggs (Brodie 1993, Brodie and Janzen 1995, Major and Kendall 1995, Moore and Robinson 2004). Plasticine clay is a common material for creating artificial animals or eggs because it is soft and pliable, and is easily imprinted when it comes in contact with hard objects. Because of this, predatory attacks leave marks in models that often allow identification of the predator (Brodie 1993).

Study site: Research was performed at $\mathrm{La}$ Selva Biological Station, in Heredia Province, Costa Rica $\left(10^{\circ} 25^{\prime} 53^{\prime}\right.$ 'N, $84^{\circ} 00^{\prime} 13^{\prime}$ W; 4 m annual rainfall; $60 \mathrm{~m}$ asl). Experimental plots were primary forests which contained trees of known height, and the crowns were high enough to be considered canopy trees. Using six plots (i.e. sites) of $50 \times 100 \mathrm{~m}^{2}$ that were spaced a minimum of $0.5 \mathrm{~km}$ apart. I placed 24 clay lizards per plot in individual trees (suspended by fishing line over a branch-see below) or on tree trunks (a total of one hundred forty four clay lizards were used throughout all six plots). Per plot, six medium and six small lizard models were placed in the canopy, and six medium and six small lizard models were placed on tree trunks near the ground. Large clay models were fastened to a $20.3 \mathrm{~cm}$ x $7.6 \mathrm{~cm}$ piece of peg-board using twist-ties, and small clay models were fastened to a 10.2 $\mathrm{cm} \times 7.6 \mathrm{~cm}$ piece of peg-board using twistties. To place lizard models in the canopy, a cross-bow was used to shoot a weighted, blunt-tipped arrow, with $4.54 \mathrm{~kg}$ (i.e. $10 \mathrm{lb}$ ) monofilament nylon fishing line fastened to it, over a tree branch. When the arrow was retrieved, I fastened a $13.6 \mathrm{~kg}$ (i.e. $30 \mathrm{lb}$ ) test braided nylon fishing line to the monofilament nylon line, and used the monofilament line to pull the braided line over the tree branch. 
Once the braided line was pulled over the branch and both ends reached the ground, I cut the monofilament fishing line from the braided fishing line, and I fastened the peg board (with the clay lizard) to the braided fishing line. I tied the two loose ends of the braided fishing line together, making a large loop that allowed me to pull the clay model to a point below, but in contact with the tree branch. The portion of the string loop that was nearest to the ground was tied to a nearby sapling or liana. For the other treatment I placed models on tree trunk locations at $0.5 \mathrm{~m}$ height by fastening the peg board (on which the models were attached) to trunks. I placed one trunk and one canopy lizard replica at sites which had access to a tree branch that appeared to exceed $10 \mathrm{~m}$ in height, and contained at least one tree trunk that was greater than $10 \mathrm{~cm} \mathrm{DBH}$. All sites were spaced a minimum of $10 \mathrm{~m}$ apart from each other. Otherwise, sites were chosen based on ease of access with crossbow.

Quantifying attack frequencies: Daily attack frequencies of clay models were determined according to the following method: I visited each clay model every other day (smoothing the models by hand at the end of each visit), and I counted the number of bite marks that accrued since the previous day. Bite marks were counted when a model was found to have an easily identifiable imprint or puncture, and classified as either vertebrate or invertebrate based on the architecture of the bite left on the plasticine. Many bite marks existed that appeared to be left by small insect mandibles, because the bite left punctures that had small $(<3 \mathrm{~mm})$ bi-lateral, hook-like marks left in the clay. Vertebrate bite marks were in the form of beak punctures, large gouges with serrations, puncture marks left by an animal's dentition, and paw marks of various sizes. Unless several different types of bite marks were left on a model that were easily discernible from each other, I tallied single or multiple bite marks as single attack events to insure that my attack frequency estimation was as conservative as possible.
This happened infrequently however: there were only three instances where clay models experienced multiple types of bites per sampling period during the wet season, and zero instances during the dry season. This is similar to the counting protocol used by Brodie 1993 and Wuster et al. 2004. Attack frequencies were measured for a 28 day portion of the wet season (June 28-July 25, 2004) and for a 23 day portion of the dry season (February 2-February 25, 2005).

Statistical analyses: I tested for differences in attack frequency between seasons, sites, locations, and clay model sizes using a log-linear analysis performed by SAS. The log-linear analysis is appropriate for enumerative data that vary in at least two dimensions, and allows testing for interactions among a number of levels, as well as for main effects (Zar 1984). The log-linear model was designed so that site (A1-A5, L6), season (wet 2004 and dry 2005), location (canopy or trunk), size (small or moderate), and result (bite/no bite) were categorical independent variables, and frequency of each result outcome (bite/ no bite) was the response variable, expressed as a range of enumerative values. Thus, there were 96 response levels to the test, representing every possible combination of outcome for the combined independent variables. The frequency of attack for each response level was obtained from the log-linear analysis, which tested whether or not the differences in number of 'bite-visits' for each response level relative to the number of 'non-bite visits' to each particular response level were greater than differences expected by chance. The significance test is a one-way test that is analogous to a $\mathrm{X}^{2}$ goodness of fit test (Tabachnik and Fidell 2001). Thus, the log-linear analysis dually accounted for seasonal difference in sampling durations by determining expected frequencies for bite-visits or non-bite visits for each season independently, as well as the probability that clay models were not attacked during many of the observations. Attack frequencies from vertebrate and invertebrates 
were analyzed as a combined data set and results do not qualitatively differ from the analysis of attack frequencies generated from considering vertebrate taxa alone. Therefore only attack frequencies from vertebrates are presented because lizard mortality would be unlikely to occur as the result of insect bites alone.

The log-linear analysis does not present mean values of attack frequency per response level, because it is a goodness of fit test. Therefore I describe differences in attack frequency using mean attack frequencies generated by dividing the number of independent bite events per observation over the total number of observation days, for each clay model size class and habitat. This method also accounts for differences in season sampling duration.

\section{RESULTS}

Attack frequencies: Bird beak marks were the most frequent class of evidence left on clay models during both wet season 2004 (See Table 1). Of 33 vertebrate bite marks identified during 2004 wet season, 11 bite marks on separate clay lizards resembled punctures that were deep and narrow, and probably formed from a bird beak (note: insect / arthropod bite marks were excluded from analysis). Based on

TABLE 1

Type of bite marks by season

$\begin{array}{clc}\text { Season } & \text { Bite Mark } & \text { Attack Frequency } \\ \text { Wet } & \text { Beak puncture } & 11 \\ & \text { Serrate } & 3 \\ & \text { Paw marks } & 3 \\ & \text { Unidentified vert } & 16 \\ & \text { Total tallied } & 33 \\ & \text { Beak puncture } & 4 \\ & \text { Serrate } & 3 \\ & \text { Paw marks } & 6 \\ & \text { Unidentified vert } & 15 \\ & \text { Total tallied } & 28\end{array}$

serrate patterns left on the clay models, three bite marks on separate clay models were left by aracari (Pteroglossus spp.). Three marks were identified as mammal paws. A total of 16 marks were identified as miscellaneous vertebrate because they were not identified as one of the classes described above, nor were they identified as invertebrate mandible bite marks. Of 28 vertebrate bite marks identified during the 2005 dry season, six bite marks were identified as mammal paws (possibly coati), four were deep and narrow punctures (as from a bird beak), and three marks were identified as aracari (Pteroglossus spp.). In this case, 15 were identified as miscellaneous vertebrate.

In the 2004 wet season, mean daily sitespecific predation frequencies over the course of 28 days ranged from 0.014 (many sites on many days) to 0.067 clay lizards per day (Site A3 on July 3, 2004). In the 2005 dry season, mean daily site-specific predation frequencies over the course of 23 days ranged from 0.0 (many sites on many days) to 0.025 clay lizards per day (Site A1). Site was not a main effect $\left(X^{2}=7.47, d f=5, p=0.188\right)$, and there was no significant interaction between site and season for attack frequency $\left(\mathrm{X}^{2}=5.43\right.$, $\mathrm{df}=5, \mathrm{p}=0.3652$ ), so I investigated attack frequencies by pooling sites.

After pooling data according to site, there were no significant main effects for season $\left(\mathrm{X}^{2}=1.10, \mathrm{df}=1, \mathrm{p}=0.294\right)$, or size $\left(\mathrm{X}^{2}=\right.$ $1.25, \mathrm{df}=1, \mathrm{p}=0.264$, see Table 2 ). The only variable that showed significant differences in attack frequency was perch location $\left(\mathrm{X}^{2}=\right.$ 7.74, $\mathrm{df}=1, \mathrm{p}=0.005$, see Table 2). Canopy models experienced significantly higher predation than trunk models (Fig. 1).

\section{DISCUSSION}

Differences in attack frequencies: With the use of plasticine clay models, I have shown that predation frequency on clay lizards is greater in the canopy compared to tree trunks near the ground in the primary forests of La Selva Biological Station. Clay lizard models in the canopy were attacked, on 
TABLE 2

Maximum likelihood Analysis of Variance

$\begin{array}{lccc}\text { Source } & \text { DF } & \text { Chi-Square } & \text { Prob }>\text { Chi-sq } \\ \text { Season } & 1 & 1.1 & 0.294 \\ \text { Height } & 1 & 7.74 & 0.005^{*} \\ \text { Season*Height } & 1 & 1.46 & 0.227 \\ \text { Size } & 1 & 1.25 & 0.264 \\ \text { Season*Size } & 1 & 0.01 & 0.941\end{array}$

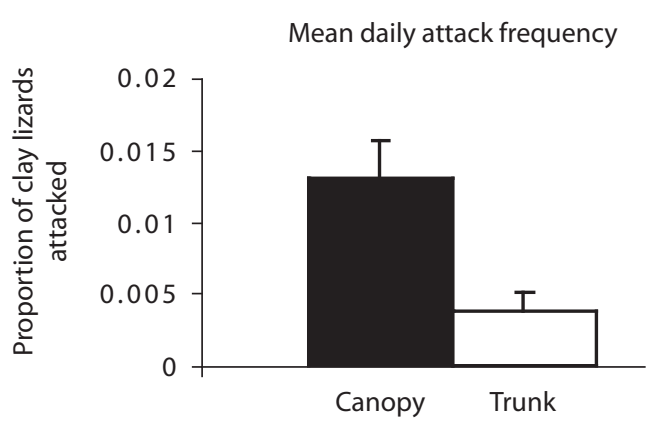

Fig. 1. Mean daily attack frequency on clay lizard models located in the forest canopy and trunk-ground junction in 6 sites throughout the primary forests at La Selva Biological Station, Heredia, Costa Rica. Clay lizard models in the canopy experienced significantly higher attack frequencies than models placed on the trunk-ground location. $\mathrm{X}^{2}=7.74$, $\mathrm{df}=1, \mathrm{p}=0.005, \mathrm{n}=144$.

average, at least three times more frequently than clay models placed on the trunk-ground junction of trees. Suprisingly, attack frequency did not differ significantly by size (nor by season or site).

Canopy models experience a mean daily attack frequency of 0.013 , and trunk ground models experience a mean daily attack frequency of 0.003. Several authors (e.g. Major and Kendall 1996, Faaborg 2004, Thompson and Burhans 2004) have cautioned the use of clay models in artificial nest experiments because they may attract certain predators and not represent true predation frequencies from all classes of predators. I recommend the same caution in direct interpretation of the use of clay models to investigate predation of a particular organism, such as lizards. However, the predation frequency revealed in this experiment represent attack frequencies that are comparable to values of mean daily mortality risks on ground-trunk anoles published by several authors who used annual survivorship to quantify predation. Mean daily predation risk ranged from 0.0065-0.0083 for N. limifrons in Costa Rica (Andrews 1979), 0.017 for $N$. limifrons in BCI, Panama (Andrews and Rand 1982), 0.0046 for Anolis gundlachi and A. evermanni in Puerto Rico (Lister 1981), 0.0022-0053 for A. occulatus in Dominica (Andrews 1979), 0.003-0.0072 for $A$. gingivinus and A. pogus on St. Martin (McLaughlin and Roughgarden 1989), and 0.0023-0.0065 for $N$. sagrei on Bimini island, Bahamas (Schoener and Schoener 1982).

These results provide experimental evidence that predation of clay lizards is more frequent in forest canopies than on tree trunks near the ground. This difference in predation frequency by habitat may potentially be a strong selective force prohibiting visual signaling in some habitats while permitting it in others. It may also explain patterns of species distribution and abundance across mainland Central America. These hypotheses await further testing. Future research should use clay models in different forest types, as well as on islands to compare results with the data published here.

\section{ACKNOWLEDGMENTS}

I thank the Organization for Tropical Studies and the Andrew Mellon foundation for providing financial support for this research. I would also like to thank David and Deborah Clark for permission to place clay models on sites used for their research, and Luis-Diego Gómez, Bob Matlock, Mahmood Sasa as well as the multitude of excellent support staff at La Selva for all aspects of assistance with this research. Thanks also go to Craig Guyer, Sharon Hermann, and members of the Guyer laboratory for providing comments on earlier drafts of this manuscript. 


\section{RESUMEN}

Existe la hipótesis de que la depredación es una fuerte fuerza selectiva que estructura las comunidades de lagartijas tropicales. Las comparaciones de las frecuencias de altura de la percha y de depredación con base en el tamaño pueden proveer una ventana única en el entendimiento de cómo la depredación podría moldear la selección del hábitat y los patrones morfológicos en las lagartijas, especialmente anoles. En este estudio uso modelos de plasticina, ubicados en troncos de árboles y suspendidos en el dosel para mostrar que la frecuencia de depredación en los modelos de plasticina difiere primariamente según el hábitat (dosel vs. tronco-suelo) pero no según el tamaño. Estos datos se discuten a la luz de las abundancias de lagartijas observadas en los bosques de bajura de Costa Rica, y se presentan como una explicación parcial a porqué menos lagartijas se encuentran en los doseles, y más lagartijas se encuentran en los hábitats suelo-tronco.

\section{REFERENCES}

Adolph, S.C. \& J. Roughgarden.1983. Foraging by passerine birds and Anolis lizards on St. Eustatius (Neth. Antilles): implications for interclass competition, and predation. Oecol. 56: 313-317.

Andrews, R.M. 1979. Evolution of life histories: a comparison of Anolis lizards from matched island and mainland habitats. Breviora 454: 1-51.

Andrews, R.M. \& A.S. Rand. 1982. Seasonal breeding and long-term fluctuations in the lizard Anolis limifrons, p. 405-412. In E.G. Leigh, Jr. \& A.S. Rand (eds.). The ecology of a tropical forest: seasonal rhythms and long-term changes. Smithsonian Institution, Washington D.C., USA.

Brodie, III, E.D. 1993. Differential avoidance of coral snake banded patterns by free-ranging avian predators in Costa Rica. Evolution 47: 227-235.

Brodie, III, E.D. \& F.J. Janzen. 1995. Experimental studies of coral snake mimicry: generalized avoidance of ringed snake patterns by free-ranging predators. Funct. Ecol. 9: 186-190.

Faaborg, J. 2004. Truly artificial nest studies. Conserv. Biol. 18: 369-370.
Irschick, D.J., L.J. Vitt, P.A. Zani \& J.B. Losos. 1997. A comparison of evolutionary radiations in mainland and Caribbean Anolis lizards. Ecology 78: 21912203.

Lister, B.C. 1981. Seasonal niche relationships of rain forest anoles. Ecology 62: 1548-1560.

Macedonia, J.M., A.C. Echternacht \& J.W. Walguarnery. 2003. Color variation, habitat light, and background contrast in Anolis carolinensis along a geographical transect in Florida. J. Herpetol. 37: 467-478.

Major, R.E. \& C.E. Kendal. 1996. The contribution of artificial nest experiments to understanding of avian reproductive success: a review of the methods and conclusions. Ibis 138: 298-307.

McLaughlin, J.F. \& J. Roughgarden.1989. Avian predation on Anolis lizards in the northeastern Caribbean: an inter-island contrast. Ecology 70: 617-623.

Moore, R.P. \& W.D. Robinson. 2004. Artificial bird nests, external validity, and bias in ecological field studies. Ecology 85: 1562-1567.

Schoener, T.W. \& A. Schoener. 1978. Inverse relationship of survival of lizards with island size and avifauna richness. Nature 274: 685-687.

Tabachnik, B.G. \& L.S. Fidell. 2001. Using Multivariate Statistics. Allyn \& Bacon, Needham Heights, Massachusetts, USA.

Thompson, III, F.R. \& D.E. Burhans. 2004. Differences in predators of artificial and real songbird nests: evidence of a bias in artificial nest studies. Conserv. Biol. 18: 373-380.

Wunderle, J.M., Jr. 1981. Avian predation upon Anolis lizards on Grenada, West Indies. Herpetol. 37: 104 108 .

Wuster, W., C.S.E. Allum, I.B.Bjartgardottir, K.L. Bailey, K.J. Dawson, J. Guenioi, J. Lewis, J. McGurk, A.G. Moore, M. Niskanen \& C.P. Pollard. 2004. Do aposematism and Batesian mimicry require bright colours? A test, using European viper markings. Proc. Roy. Soc. Lond.B. 271: 2495-2499.

Zar, J.H. 1984. Biostatistical Analysis. Prentice-Hall, Englewood Cliffs, New Jersey, USA. 